\title{
«Не работают и не учатся»: молодежь NEET на рынке труда в России ${ }^{1}$
}

\author{
А.А. ЗУДИНА*
}

\begin{abstract}
*Анна Алексеевна Зудина - кандидат социологических наук, научный сотрудник, Центр трудовых исследований, Национальный исследовательский университет «Высшая школа экономики». Адрес: 110100, Москва, ул. Мясницкая, д. 20. E-mail: azudina@hse.ru

Цитирование: Зудина А.А. (2019) «Не работают и не учатся»: молодежь NEET на рынке труда в России // Мир России. Т. 28. № 1. С. 140-160. DOI: $10.17323 / 1811-038 \mathrm{X}-2019-28-1-140-160$
\end{abstract}

В международной статистике молодежь в возрасте 15-24 лет, которая не учится, не работает и не участвует в профессиональной подготовке, получила особое название NEET (Not in Employment, Education or Training). Eе представители оторвань от сферы образования и рынка труда, что в будущем может привести не только к проблемам с трудоустройством, но и к сложностям с полноценной сочииализацией. В настоящей работе масштаб, динамика и соичильно-демографический портрет молодежи NEЕT в России анализируются на основе данных Обследования населения по проблемам занятости (ОНПЗ) Росстата за 1995-2015 годы. Полученнье результаты свидетельствуют о том, что в обозреваемый период доля этой группь в России значительно сократилась благодаря преимущественно активному вовлечению молодежи в обучение. Согласно данным ОНПЗ, российская молодежь NEET никак не реагировала на макроэкономические шоки: она не росла в период кризисов 2008-2009 и 2015 годов. В составе российского NEET устойчиво преобладают те, чья связь с рынком труда наиболее слаба, - так называемые экономически неактивнье, а подавляющее большинство безработной молодежи NEЕT вообще не имеет опыта работь. Социально-демографические характеристики этой категории указывают на то, что наиболее значимыми причинами попадания в нее являются несоответствие полученного образования требованиям рынка труда и его низкий уровень, а также дефищит рабочих мест в сельской местности. При этом значительная часть безработной молодежи NEET в России имеет высшее профессиональное образование,

1 В данной статье использованы результаты проекта, выполненного в рамках Программы фундаментальных исследований НИУ ВШЭ. Автор выражает признательность за ценные замечания и комментарии В.Е. Гимпельсону. 
и в том случае, если массовизаџия высшего образования будет продолжаться, важной частью этой категории россиян могут стать выпускники некачественных вузов, чьи знания и навыки не найдут применения.

Ключевые слова: молодежная безработица, рабочая сила, рынок труда, Россия, молодежь NEET, обследование населения по проблемам занятости

\section{Введение}

Обеспечение плавного перехода молодежи от учебы к работе включено в число актуальных задач политики в сфере занятости во многих странах. В связи со старением населения численность рабочей силы сокращается, и основой будущей производительности труда и экономического развития в целом остается качество человеческого капитала молодых работников.

При обсуждении данной темы принято опираться на уровни безработицы и экономической неактивности молодежи, значения которых в разных странах намного превышают средние показатели по рынку труда в целом. К примеру, в 2015 г. доля безработных в возрасте 15-24 лет во Франции составляла почти $25 \%{ }^{2}$, при этом средний уровень безработицы в стране равнялся $10 \% 3$. В Испании и Греции значения молодежной безработицы достигали 50\% при среднем уровне безработицы в 20-24\%. В России в 2015-2016 гг. соответствующие показатели по безработным в возрасте 15-19 лет превышали 30\%, в возрасте 20-24 лет - около $15 \%$ при среднем уровне безработицы в 5-6\%.

В соответствии с методологией Международной организации труда (MOT) приведенные значения показателей безработицы рассчитываются по отношению к численности рабочей силы, а в молодых возрастах она, как правило, невелика. К примеру, в 2015 г. в России в возрасте 15-19 лет уровень экономической активности составляет только $9 \%{ }^{4}$. Можно предположить, что традиционные показатели безработицы слабо отражают реальную ситуацию на молодежном рынке труда, что в свою очередь приводит к смещению представлений и, соответственно, рекомендаций для социальной политики. В то же время экономическая неактивность молодежи, т.е. нахождение за пределами рынка труда, также не является острой проблемой сама по себе, т.к. многие продолжают обучение, являющееся для них основным занятием.

В такой ситуации одним из важнейших показателей перехода от учебы к работе для конкретного рынка труда становится доля тех, кто и не работает, и не учится, - группы NEET (Not in Employment, Education or Training) [OECD (2) 2013]. Показатель доли группы NEET обычно рассчитывается по отношению ко всей численности населения в возрасте 15-24 лет, что делает его гораздо более информативным по сравнению с показателем безработицы. Согласно

2 Статистика уровней молодежной безработицы по странам ОЭСР в 2015 г. приводится по [OECD 2015].

3 Статистика уровней безработицы по странам ОЭСР в 2015 г. приводится по сборнику [OECD 2016].

4 Согласно данным Росстата из сборника [Рабочая сила, занятость и безработица в России 2016]. 
зарубежным исследованиям, молодые люди, входящие в эту категорию, составляют одну из наиболее уязвимых групп: в частности, они исключены из рынка труда, а значит, потенциально и из жизни общества в целом [Eurofound 2012]. Последствия пребывания в группе NEET, выявленные зарубежными учеными, включают уменьшение шансов на стабильную занятость, низкий уровень заработной платы и доходов, бедность, зависимость от денежных трансфертов со стороны других членов семьи [Eurofound 2012; Wadsworth 2013]. Представители группы NEET часто являются получателями социальных пособий от государства, а в случае выхода на рынок труда могут оказаться вовлеченными в неформальную занятость [OECD (1) 2013]. Тем самым категория NEET выделяет молодежь, испытывающую значительные ресурсные ограничения и пребывающую по тем или иным причинам в ситуации социальной эксклюзии - тех, кто «остался позади» [Scarpetta, Sonnet, Manfredi 2010]. Актуальность изучения группы NEET продиктована также тем, что пребывание в состоянии оторванности от сферы занятости и образования может не ограничиться молодостью, а будет транслироваться в дальнейшем в средние и даже старшие возраста, приводя к безработице или экономической неактивности, которые будут чередоваться с незащищенной или непостоянной занятостью. Вопрос о том, можно ли со временем преодолеть негативные последствия пребывания в статусе NEET, согласно результатам зарубежных исследований, остается открытым. Тем самым, молодежь NEET выступает одной из социально уязвимых групп населения, занимающих смежное положение по отношению к другим депривированным категориям - нестабильно занятым, неформальным работникам, безработным.

Работ, посвященных молодежи NEET в России, пока очень мало 5 , и они основываются преимущественно на данных 2012-2014 гг. Информации о масштабе, динамике и социально-демографических характеристиках данной группы за более длительный период, который включал бы 1990-е гг., по России нет.

Целью настоящей статьи является представление первой дескриптивной картины, демонстрирующей качественные изменения численности и состава молодежи NEET на протяжении последних двадцати лет - с 1995 по 2015 г. Важно отметить, что зарубежные исследования, в которых фигурировала динамика доли данной группы на протяжении длинных временных рядов, в настоящее время немногочисленны. Вместе с тем важным вопросом остается соотношение показателей вовлеченности в группу NEET и стадий экономического цикла, которые можно было бы проследить только на данных за длительный период времени. Анализ взаимосвязи численности и структуры категории NEET с макроэкономическими шоками преимущественно концентрируется на изучении последствий мирового финансового кризиса 2008 г. [Carcillo, Fernández, Königs, Minea 2015] и показывает значительное увеличение одной из составляющих категории NEET - безработных NEET. Однако более комплексное описание того, как колебались размер и структура молодежи NEET в странах с трансформационной экономикой при переходе к рынку и что происходит с данными показателями в последующие периоды экономического подъема и спада, отсутствует. Первичная характеристика этих процессов на российских данных позволит расширить исследовательские представления о природе такого социального феномена, как группа NEET. Является ли она простой проекцией состояний безработицы и неактивности на младшие

5 Пионерным является исследование Е.Я. Варшавской [Варшавская 2015]. 
возраста, и, таким образом, ее численность будет увеличиваться в кризис и снижаться в периоды подъема? Или же отношения между показателем вовлеченности в категорию NEET и макроэкономическим климатом окажутся сложнее? Изучение динамики доли данной группы и ее характеристик на российском рынке труда позволит приблизиться к ответу на вопрос, составит ли нынешняя молодежь NEET одну из социальных проблем российского общества в будущем.

\section{Кто такие NEET: обзор эмпирических исследований}

Значительная вариация в уровнях молодежной занятости, которая становится фокусом различных межстрановых исследований, является результатом различий в значениях трех связанных между собой показателей: (1) доли молодых людей, которые обучаются в образовательных организациях, (2) доли молодежи, совмещающей учебу с работой, и (3) доли тех, кто оказался вне сферы образования и рынка труда [Carcillo, Fernández, Königs, Minea 2015]. Проблемы молодежи, не участвующей в занятости или получении образования, впервые стали рассматриваться в академических работах в конце 1980-х гг, когда поколение «бэби-бумеров» вступило на рынок труда [Eurofound 2012]. Отсутствие опыта работы и склонность к экспериментированию с выбором профессии и рабочего места, а вследствие этого и частые смены статуса занятости, породили особую напряженность на молодежном рынке труда. В Великобритании она усугубилась реформой пособий по безработице, лишившей значительную часть британской молодежи в возрасте 16-18 лет права на помощь со стороны государства. Термин NEET появился значительно позднее: впервые он упоминался в официальных документах ${ }^{6}$ в 1999 г., при этом возрастные рамки данной категории были расширены ${ }^{7}$. В 2010 г. Евростат разработал стандартизированное определение молодежи NEET, согласно которому в эту категорию входят молодые люди в возрасте 15-24 лет, безработные или экономически неактивные, которые не учатся и не проходят профессиональную подготовку или переподготовку.

Анализ масштабов, динамики и отличительных характеристик данной группы в конкретных странах, как правило, проводится на основе общенациональных обследований рабочей силы. Показатель доли представителей NEET рассчитывается и для отдельных возрастных групп ${ }^{8}$. Согласно данным европейской статистики, в 2015 г. более 6,5 млн молодых людей в возрасте 15-24 лет были исключены из сферы образования и рынка труда. Таким образом, доля группы NEET в общей численности молодежи в этом возрасте в Европе составляла около 12\%. Сравнение этих цифр с показателями молодежной безработицы в явном виде демонстрирует преимущества индикатора NEET. Абсолютная численность молодежи NEET превышает соответствующий показатель безработной молодежи (6,6 против 4,6 млн чел.), однако доля молодежи NEET значительно меньше доли безработных

6 На русском языке подробная история возникновения термина представлена в [Варшавская 2015].

7 Определение, разработанное британскими исследователями, не включало молодежь в возрасте 18-24 или 25-29 лет.

8 Чаще всего исследователи выделяют две группы - молодежь в возрасте 15-19 и 20-24 лет. 
по определению MOT (12 против 20\%). Важно отметить, что доля группы NEET среди молодежи в возрасте 15-19 лет значительно ниже соответствующего показателя среди 20-24-летних (в 2015 г. соответствующие значения составляли 6,3 против 17,3\%). Показатели доли группы NEET варьируются и по странам: так, в Италии, Греции, Болгарии, Румынии и Хорватии они превышают 17\% (наиболее высокие значения в Европе), а в Люксембурге, Дании и Германии составляют чуть более 6\% [Eurofound 2016].

Интерес к изучению молодежи NEET продиктован характеристиками молодежной занятости, которые определяются как спросом на рабочую силу в молодых возрастах, так и структурой ее предложения. Спрос на молодежную рабочую силу в свою очередь зависит от фаз макроэкономического цикла. Значительная часть молодежных рабочих мест сосредоточена в отраслях, которые первыми реагируют на подъем или спад в экономике [Freeman, Wise 1982], при этом у молодых работников зачастую отсутствует опыт работы, а имеющиеся у них навыки и компетенции могут не соответствовать запросам работодателей [Eurofound 2012] и потребностям новых или динамично развивающихся отраслей. Параллельно этому происходит замещение традиционного линейного перехода от учебы к работе множеством диверсифицированных и индивидуализированных трудовых траекторий, предполагающих периоды возвращения в незанятость, частую смену типа занятости и совмещение учебы и работы. Все перечисленные факторы влияют на особенности перехода от учебы к работе на конкретном рынке труда. В такой ситуации исследователи и лица, принимающие решения, в большей степени нуждаются в показателях, позволяющих описать «все оттенки серого», т.е. все многообразие возможных статусов молодежи. Одним из наиболее информативных индикаторов является доля тех, кто не учится и не работает, т.е. не смог успешно совершить переход от учебы к работе [OECD (2) 2013].

Несмотря на указанные достоинства показателя, категория NEET весьма неоднородна, т.к. мотивы незанятости могут сильно различаться9. Большую часть NEET-молодежи, как правило, составляют безработные, т.е. те, кто не имеет работы, активно ищет ее и готов к ней приступить. Согласно исследованиям, именно этот тип наиболее активно увеличивается при ухудшении макроэкономической ситуации [Carcillo, Fernández, Königs, Minea 2015]: например, в Испании и Греции, которые характеризуются наиболее значительным изменением доли молодежи NEET в кризис по сравнению с остальными странами ОЭСР, соответствующий рост полностью определялся изменением доли безработных NEET.

Остальные категории молодежи NEET представляют собой различные варианты экономически неактивного населения, т.е. находятся за пределами рынка труда. Среди них люди с различными заболеваниями и инвалиды, а также те, кто вынужден на постоянной основе заботиться о других членах семьи (к примеру, молодые матери); те, кто не стремится учиться или становиться занятым и при этом не имеет никаких семейных обязательств или ограничений по здоровью; так называемые отчаявшиеся, т.е. те, кто отказался от поисков работы. Следует отметить, что наиболее благополучны те, для кого данный статус стал добровольным выбором (период «поиска себя»). Отличительной чертой всех перечисленных типов является их невовлеченность в формальные каналы накопления человеческого капитала

9 Это является одним из основных аргументов критики концепции NEET (см., напр. [Elder 2015]). 
в период пребывания в статусе NEET [Eurofound 2012], при этом материальные и временные ресурсы для использования соответствующих неформальных каналов у молодежи NEET могут быть ограничены. Как показывают эмпирические исследования, в период мирового финансового кризиса доля экономически неактивных NEET, как правило, оставалась стабильной или сокращалась. К исключениям можно отнести Японию и Данию, на рынках труда которых рост молодежи NEET был вызван увеличением экономически неактивных NEET [Carcillo, Fernández, Königs, Minea 2015]. При этом в случае Японии ситуация на молодежном рынке труда также дополнительно усугублялась жесткими нормативными возрастными границами, определявшими наем работников. Это значительно осложняло возможности нахождения рабочих мест с полной занятостью и оформлением в штат для молодежи, имевшей опыт пребывания в группе NEET [Kosugi 2005], что способствовало росту численности не безработной (т.е. ищущей работу), а экономически неактивной молодежи, уходящей с рынка труда.

В зависимости от доли молодежи NEET в общей численности соответствующей возрастной группы и ее структуры страны Евросоюза можно условно разделить на три кластера [Eurofound 2016]. В большинстве стран, попавших в первый кластер (Австрии, Бельгии, Дании, Финляндии, Германии, Франции, Люксембурге, Нидерландах, Словении, Швеции, Великобритании), наблюдается быстрый и плавный переход от учебы к работе, и по этой причине выявляются относительно низкие показатели доли молодежи NEET (5,5-12\%). При этом значительная часть данной категории становится экономически неактивной, а доля отчаявшихся найти работу и длительных безработных здесь ниже среднего показателя по Европе в целом. Типичный представитель молодежи NEET в этих странах имеет низкий уровень образования и решает покинуть сферу образования и рынка труда не изза структурных барьеров, мешающих нахождению занятости, а из-за проблем со здоровьем или для того, чтобы посвятить себя заботам о семье.

Во второй кластер объединены южные или средиземноморские страны, большинство которых отличаются высокими показателями доли молодежи NEET (15-22\%) - Хорватия, Кипр, Греция, Италия, Португалия, Испания, помимо них, в эту группу входит Ирландия. Рынки труда указанных стран серьезно пострадали во время мирового финансового кризиса или же в принципе характеризуются затрудненным и протяженным переходом молодежи от учебы к работе. Подавляющую часть молодежи NEET в названных государствах составляют длительные безработные и отчаявшиеся найти работу. Выпускники высших учебных заведений в большинстве стран второго кластера составляют основную группу риска. Все это свидетельствует о значительных барьерах входа на рынок труда, с которым сталкивается молодежь в этих странах.

В кластер третьего типа входят страны Восточной Европы (Чехия, Эстония, Венгрия, Латвия, Литва, Польша, Румыния, Словакия), где среди молодежи NEET велика доля молодых женщин и тех, кто оставил рынок труда из-за семейных обязанностей. Некоторые страны третьего кластера также демонстрируют более высокую долю долговременных безработных и отчаявшихся найти работу.

Несмотря на внешнюю простоту самой дефиниции, выделение категории NEET влечет за собой решение сложных исследовательских проблем, связанных с фундаментальными вопросами экономики и социологии труда, социальной стратификации и неравенства. Среди них - качество человеческого капитала молодежи 
NEET, влияние пребывания в статусе NEET на последующую занятость и уровень заработной платы, бедность и социальная стратификация, место молодежи NEET в системе социального неравенства. Также необходимо получить ответы на вопросы: каковы причины попадания молодежи в группу NEET и можно ли его предотвратить; является ли состояние NEET продолжительным явлением и если да, то как с этим бороться; оставляет ли членство в данной группе долговременный «шрам» на трудовой биографии и жизненной траектории; куда переходят повзрослевшие представители группы NEET, т.е. как пребывание в группе NEET отражается на направлении потоков работников средних возрастов; влияет ли наличие статуса NEET в молодости на риски бедности на протяжении жизни.

В исследованиях, посвященных выявлению причин попадания молодежи в категорию NEET, обычно выделяют две группы параметров - характеристики самого молодого человека и характеристики его родительской семьи. К первой группе факторов относят низкий уровень образования и его плохое качество, статус мигранта, плохое состояние здоровья, опыт подростковой беременности и последующее рождение ребенка, раннее вступление в брак. Во вторую группу включают наличие безработных родителей или родителей с низким уровнем образования, многодетность родительской семьи, низкий уровень доходов домохозяйства, плохое жилье, проживание в небольших или отдаленных населенных пунктах [Eurofound 2012]. При этом при обсуждении данной темы нередко упускается из виду тот факт, что индивидуальные и семейные факторы тесно связаны между собой, т.к. процесс накопления человеческого капитала носит динамический характер, на который влияет множество различных институтов. Одним из ключевых причин в этом процессе, начинающемся задолго до школьного обучения, как подчеркивали Д. Хекман и П. Карнейро, являются характеристики семьи [Heckman, Carneiro 2003]. Следовательно, попадание в группу NEET может происходить из-за исходного социально-экономического неравенства семей молодых людей в возможностях формирования и развития различных составляющих человеческого капитала (когнитивных и некогнитивных навыков), которые и определяют дальнейшие достижения в обучении и успешность перехода от учебы к работе. Все остальные перечисленные выше факторы (раннее вступление в брак и рождение ребенка, статус мигранта, плохое жилье) во многом будут коррелировать с низким социально-экономическим положением семьи происхождения. Исследования на тему взаимосвязи положения семьи, формирования различных навыков и попадания в статус NEET появились совсем недавно и обнаружили значимые эмпирические подтверждения данной взаимосвязи (см., напр. [Gladwell, Popli, Tsuchiya 2016]).

В свою очередь, согласно П. Бурдье, именно процесс аккумулирования различных типов капитала определяет место, которое индивид займет в структуре социального неравенства в дальнейшем [Бурдье 2004]. Проведенные исследования показывают, что факт попадания в категорию NEET имеет важные долгосрочные следствия для благополучия индивида: среди них уменьшение шансов на стабильную занятость, низкий уровень заработной платы и доходов, бедность, проблемы с физическим и психическим здоровьем, склонность к правонарушениям [OECD 2010] и потреблению алкоголя и наркотиков [Coles, Hutton, Bradshaw, Craig, Godfrey, Johnson 2002]. В сравнении с теми, кто учится или работает, молодежь NEET также демонстрирует гораздо меньший уровень доверия к социальным институтам, а также слабый интерес к политике и жизни общества [Alfieri, Rosina, Sironi, Marta, Marzana 2015; Eurofound 2012]. Таким образом, неравенство среди семей транслиру- 
ется в статус NEET их детей и позднее воспроизводится в социально-экономическом положении самих повзрослевших представителей молодежи NEET.

Для России эмпирические оценки доли молодежи NEET впервые были представлены в исследовании Е.Я. Варшавской [Варшавская 2015]. По данным Обследования населения по проблемам занятости (ОНПЗ) за 2013 г., доля молодежи в возрасте 15-24 лет, принадлежащая к категории NEET, составляла 12,7\%, т.е. находилась на среднеевропейском уровне. При этом, как и в зарубежных странах, в России вовлеченность в данную категорию в большей степени была присуща 20-24-летним, чем 15-19-летним. В гендерной структуре NEET отчетливо доминировали женщины, а наиболее характерным типом незанятости являлась экономическая неактивность: доля неактивных представителей NEET в общей численности молодежи составляла 7,2\%, а доля безработных $-5,5 \%$. При этом россиянки в возрасте 20-24 лет гораздо чаще являлись экономически неактивными, чем безработными. Тем самым, как отмечает автор, в России наблюдаются более значительные гендерные различия в доле NEET среди молодежи в возрасте 20-24 лет по сравнению со странами Европейского союза. Е.Я. Варшавская также подробно анализирует особенности российской молодежи NEET на данных ОНПЗ за 2014 г. Результаты указывали на то, что факт принадлежности к категории NEET в значительной степени связан с низким уровнем полученного образования и отсутствием опыта работы ${ }^{10}$. Те представители данной категории, которые обладали опытом трудовой деятельности, приобретали его на нестабильных и неквалифицированных рабочих местах, что оказывало влияние на их последующую незанятость [Варшавская 2016].

Указанные исследования российской NEET-молодежи основываются на данных за 2012-2014 гг. В настоящей статье рассматривается двадцатилетний период с 1995 по 2015 г., который охватывает почти весь переходный этап развития страны. Это позволяет изучить возможные изменения в размере и составе группы NEET, происходившие под влиянием разнонаправленных макроэкономических шоков (начальный период перехода к рыночной системе, экономический рост 2000-х гг., последствия кризисов 2008-2009 и 2015-2016 гг.).

\section{Построение показателя NEET}

Следуя сложившейся исследовательской традиции изучения молодежи NEET на данных национальных обследований рабочей силы, в представленной статье были использованы первичные данные Обследования населения по проблемам занятости Росстата $^{11}$. В этом отношении настоящая работа являет собой развитие существующих исследований молодежи NEET по России, которые были выполнены на данных

\footnotetext{
10 Это также согласуется с результатами исследования молодежи NEET, выполненного на данных РМЭ3 НИУ ВШЭ за 2012-2014 гг. Т.В. Блиновой и А.А. Вяльшиной [Блинова, Вяльшина 2016].

11 ОНПЗ представляет собой выборочное обследование домохозяйств, проводимое Росстатом с 1992 г. во всех субъектах Российской Федерации (с 1999 г. до августа 2009 г. ежеквартально, а затем ежемесячно). С 2016 г. название обследования было изменено на Обследование рабочей силы (ОРС). Его репрезентативная годовая выборка составляла около 270 тыс. чел. при ежеквартальном сборе данных и примерно 800 тыс. чел. при ежемесячном. К сожалению, ОНПЗ не является панелью, что делает невозможным как анализ последствий переходов молодежи из статуса NEET, так и ретроспективный анализ социально-экономического положения семьи.
} 
ОНПЗ, ставших базовым источником информации о статистике российского рынка труда [Варшавская 2015; Варшавская 2016]. Для анализа были отобраны пять временных точек - 1995, 2000, 2005, 2010 и 2015 гг. Для построения показателя статуса NEET вся численность населения в возрасте 15-24 лет была разделена на три группы в зависимости от их текущего положения на рынке труда на момент проведения опроса: занятые, безработные и экономически неактивные (определения данных групп следовали стандартным рекомендациям МОТ). Далее безработные и экономически неактивные респонденты в возрасте 15-24 лет были объединены. После этого анализировалось распределение ответов данной категории на вопрос о причинах незанятости, и из категории удалялись респонденты, которые на момент опроса были учащимися образовательных организаций очной формы обучения. Оставшиеся в категории респонденты могли быть незаняты по причинам инвалидности, ведения домашнего хозяйства, наличия дохода от собственности и другим причинам. Тем самым эта категория представляла собой индивидов в возрасте 15-24 лет, которые не работали и не учились на момент опроса, т.е. представителей молодежи NEET.

Важно подчеркнуть, что данные ОНПЗ не позволяют отследить факт прохождения или непрохождения незанятым индивидом тренингов, курсов повышения квалификации, подготовительных курсов, а также обучение на заочной форме или в вечернее время. Таким образом, мы получаем верхнюю границу показателя вовлеченности молодежи в группу NEET, которые могут быть в дальнейшем уточнены с использованием альтернативных источников данных ${ }^{12}$. Продолжительность пребывания в состоянии NEET также не может быть определена на данных ОНП ${ }^{13}$, поэтому принадлежность к данной группе фиксировалась на момент опроса. Это согласуется с существующей методологией проведения соответствующих исследований на данных зарубежных стран. Необходимо уточнить, что индивиды, ответившие, что они в настоящий момент не работают и не учатся, могут в дальнейшем продолжить свое образование или выйти на рынок труда. Однако для целей настоящего исследования принципиальным является то, что в момент опроса они находились за пределами рынка труда и сферы образования. При этом использование годовых данных, полученных путем взвешивания данных за все кварталы (а с 2009 г. - за все месяцы) соответствующих лет, по сути, позволяет получить множество «моментов времени» опроса, что сглаживает возможные сезонные колебания в показателях участия в образовании и занятости.

Анализ проводился отдельно для молодежи в возрасте 15-19 и 20-24 лет. Подобное деление является традиционным для существующей исследовательской литературы, посвященной молодежи NEET (см., напр. [Eurofound 2016]). Возможное объяснение связано с различиями в показателях участия в образовании у молодежи данных возрастных групп. Молодежь 15-19 лет получает среднее образование, которое во многих странах является обязательным, в то время как представители возрастной группы 20-24 лет могут как продолжить обучение в учреждениях профессионального образования, так и выйти на рынок труда. При этом в возрастной группе старше 25 лет уровни участия молодежи в образовании резко снижаются и достигают минимальных значений.

12 Например, Российского мониторинга экономического положения и здоровья населения НИУ ВШЭ.

13 Вопрос о продолжительности незанятости задавался только безработным респондентам. 


\section{Масштаб и динамика численности группы NEET в 1995-2015 гг.}

При изучении характеристик молодежи NEET первоочередной интерес представляют показатели масштаба и динамики численности данной группы в 1995-2015 гг. В таблице 1 представлено сравнение основных характеристик положения молодежи на российском рынке труда, рассчитанных для двух возрастных групп - 15-19-летних и 20-24-летних. Сразу обращают на себя внимание большие значения безработицы молодежи в возрасте 15-19 лет: в период 1995-2015 гг. они составляли около $30 \%$, а сам пик молодежной безработицы пришелся на 2015 г. Как уже отмечалось выше, показатель безработицы, согласно рекомендациям МОТ, рассчитывается не по отношению к численности возрастной группы в целом, а по отношению к экономически активному населению в данном возрасте. Как видно из таблицы 1 , в анализируемый период последний не превышал $25 \%$ от общей численности молодежи в возрасте 15-19 лет. При этом наибольшее значение экономической активности было характерно для трансформационного периода, т.е. для 1995 г. По сравнению с более благополучным 2010 г. в 2014-2015 гг. вовлеченность молодежи 15-19 лет в рынок труда еще больше снизилась и достигла своего минимума (8,7\%). Аналогичную динамику демонстрирует показатель занятости молодежи 15-19 лет - он плавно уменьшается с 18 до 6\% в 1995-2015 гг.

Таблица 1. Основные характеристики положения молодежи на российском рынке труда, ОНПЗ, 1995-2015 гг.

\begin{tabular}{|l|c|c|c|c|c|c|c|c|c|c|}
\hline \multirow{2}{*}{ Статус молодежи на рынке труда } & \multicolumn{9}{|c|}{$\mathbf{1 5}-\mathbf{1 9}$ лет } \\
\cline { 2 - 12 } & $\mathbf{1 9 9 5}$ & $\mathbf{2 0 0 0}$ & $\mathbf{2 0 0 5}$ & $\mathbf{2 0 1 0}$ & $\mathbf{2 0 1 5}$ & $\mathbf{1 9 9 5}$ & $\mathbf{2 0 0 0}$ & $\mathbf{2 0 0 5}$ & $\mathbf{2 0 1 0}$ & $\mathbf{2 0 1 5}$ \\
\hline Безработные* & 28,7 & 27,6 & 29,2 & 31,8 & 32,4 & 15,3 & 16,2 & 12,3 & 14,9 & 14,3 \\
\hline Занятые** & 18,1 & 14,0 & 11,8 & 7,9 & 5,9 & 65,1 & 57,5 & 54,4 & 53,2 & 49,9 \\
\hline Экономически активные** & 25,3 & 20,1 & 15,9 & 11,6 & 8,7 & 77,0 & 69,7 & 62,6 & 62,5 & 58,2 \\
\hline Группа NЕЕТ*** & 14,6 & 12,3 & 8,8 & 6,5 & 5,4 & 23,6 & 24,5 & 18,5 & 19,1 & 16,7 \\
\hline Группа NЕЕТ-безработные*** & 6,4 & 4,9 & 3,0 & 2,3 & 1,9 & 11,4 & 11,5 & 7,5 & 8,4 & 7,3 \\
\hline Группа NЕЕТ-ЭНАН*** & 8,2 & 7,4 & 5,8 & 4,2 & 3,5 & 12,3 & 13,0 & 11,0 & 10,7 & 9,4 \\
\hline Доля обучающихся**** & 67,3 & 73,7 & 79,5 & 85,7 & 88,7 & 11,2 & 18,0 & 27,1 & 27,7 & 33,4 \\
\hline $\begin{array}{l}\text { Численность возрастной группы, } \\
\text { тыс. чел. }\end{array}$ & 10997 & 12322 & 11825 & 8389 & 6829 & 10385 & 11106 & 12404 & 12169 & 9293 \\
\hline
\end{tabular}

\section{Примечания:}

* - показатель рассчитан в соответствии с методологией МОТ, т.е. приводится в \% от численности экономически активного населения;

** - показатель рассчитан в соответствии с методологией МОТ, т.е. приводится в \% от численности возрастной группы;

*** - показатель рассчитан в соответствии с методологией Евростата, т.е. приводится в \% от численности возрастной группы;

**** - показатель рассчитан в \% от численности возрастной группы. 
При этом динамика доли обучающихся в возрасте 15-19 лет, напротив, показывает восходящую тенденцию: так, в 1995 г. в обучение в образовательных организациях очной формы были вовлечены лишь $67 \%$ всей молодежи в возрасте 15-19 лет, и это наименьшее значение данного показателя за весь анализируемый период. В дальнейшем показатель доли обучающихся в возрасте 15-19 лет только увеличивался: в 2015 г. наблюдается максимальное значение доли обучающихся в возрасте 15-19 лет (почти 90\%). Данные результаты согласуются с отмечаемыми исследователями тенденциями российской системы образования [Андрущак, Гохберг, Забатурина, Ковалева 2016].

В 1995 г. 14,6\% всей молодежи в возрасте 15-19 лет было исключено из сферы образования и трудовой деятельности. В период 1995-2015 гг. этот показатель стабильно снижался и в 2015 г. составил немногим более 5\% от общей численности российской молодежи в возрасте 15-19 лет. Таким образом, в 2015 г. доля российской молодежи NEET в возрасте 15-19 лет была чуть ниже соответствующего значения по странам Европы [Eurofound 2016]. Описанная динамика общего показателя группы NEET на протяжении 1995-2015 гг. определялась изменением численности обеих его составляющих - как безработных, так и экономически неактивных. В 1995 г. доля безработных молодых NEET в возрасте 15-19 лет составляла $6,4 \%{ }^{14}$. Доля тех, кто не учился и при этом был экономически неактивным, равнялась 8,2\%. В период 1995-2015 гг. доли безработных и экономически неактивных представителей NEET стабильно снижались и к 2015 г. составляли 1,9 и $3,5 \%$ соответственно от всей молодежи в возрасте 15-19 лет. При этом ни 2010 г., ни 2015 г. не характеризуются каким-либо ростом показателей вовлеченности молодежи в категорию NEET, который мог бы стать ответом на соответствующие негативные макроэкономические шоки. Таким образом, экономическая неактивность осталась преобладающим типом незанятости для группы NEET, а основной тенденцией, описывающей изменение положения молодежи 15-19 лет на российском рынке труда в 1995-2015 гг., являлась ее растущая вовлеченность в сферу образования.

Анализ основных характеристик положения молодежи в возрасте 20-24 лет демонстрирует сходные тенденции. В период 1995-2015 гг. показатели безработицы среди экономически активных представителей данного возраста были довольно стабильными (12-16\%), при этом наибольшее значение экономической активности наблюдалось в 1995 г., когда около 77\% 20-24-летних находились на рынке труда. В дальнейшем экономическая активность молодежи 20-24 лет стабильно снижалась, и к 2015 г. показатель составил примерно 58\%. Закономерно, что показатель занятости 20-24-летних в анализируемый период также снижался - с 65 до 49,9\% от общей численности молодежи в данных возрастах. Сокращение экономической активности и занятости в данных возрастах на протяжении 1995-2015 гг. стало результатом нескольких процессов. С середины 1990-х гг. ожидания относительно экономической отдачи от профессионального образования разных уровней активно возрастали, а следовательно, увеличивался

\footnotetext{
14 Важно подчеркнуть, что категории безработных, выделенных по определению МОТ, и безработных представителей NEET в одной и той же возрастной группе могут отличаться по численности. Так, к категории безработных по МОТ могут относиться те, кто одновременно с поиском работы обучается в образовательных организациях очной формы.
} 
и спрос на него со стороны молодежи ${ }^{15}$ [Андрущзак, Гохберг, Забатурина, Ковалева 2016; Рощин 2006]. Помимо этого, важным фактором стала и усилившаяся напряженность на трансформирующемся российском рынке труда. Вовлечение в образование в новых реалиях выступило альтернативой трудовой деятельности, тем самым реализовав механизм «отложенного» предложения труда [Рощзин 2006]. Неудивительно, что динамика доли обучающихся в группе 20-24-летних в рассматриваемый период демонстрировала активную тенденцию к росту: если в 1995 г. соответствующий показатель составлял около 11\%, то к 2015 г. он превысил $30 \%$.

Как и в зарубежных странах, доля представителей группы NEET среди 20-24-летних в России намного выше, чем среди молодежи в возрасте 15-19 лет: в 1995 г. почти каждый четвертый россиянин в возрасте 20-24 лет не учился и не работал, при этом в структуре данной категории безработные и экономически неактивные были представлены практически поровну. В дальнейшем показатель вовлеченности в категорию NEET среди 20-24-летних снизился и составил 17\% в 2015 г. Таким образом, доля вовлеченных в категорию NEET среди российской молодежи 20-24 лет находилась на уровне среднеевропейских значений [Eurofound 2016]. При этом разрыв между NEET-безработными и NEET-экономически неактивными увеличился, а последние стали преобладать. В 2010 г. наблюдается небольшое увеличение доли безработных NEET (на 0,9 п.п. по сравнению с 2005 г.), однако в течение следующих пяти лет показатель вновь стал снижаться и сравнялся со значениями 2005 г.

Таким образом, на протяжении 1995-2015 гг. доля представителей группы NEET сокращалась ${ }^{16}$, при этом наиболее стабильной являлась доля экономически неактивных NEET в возрасте 20-24 лет. Важно подчеркнуть, что именно молодежь в возрасте 20-24 лет часто является одной из основных движущих сил рынка труда. Получив профессиональное образование того или иного уровня, молодые люди отправляются на поиски рабочего места, и их уход с рынка труда может свидетельствовать о наличии серьезных проблем, возникающих при рассогласованности требований рынка труда и полученного образования. Примечательно также, что доля безработных NEET стабильно снижалась как среди 15-19-летних, так и среди 20-24-летних, практически никак не реагируя на ухудшение экономической ситуации 2008-2009 гг. и 2015-2016 гг.

\section{Социально-демографические характеристики представителей NEET-молодежи}

В таблице 2 представлена динамика характеристик безработных представителей молодежи NEET в 1995-2015 гг. по двум возрастным группам.

\footnotetext{
15 В настоящей работе сознательно не обсуждается сюжет об изменении практик совмещения учебы и работы, произошедший в данный период (см. на эту тему [Рощин 2006; Рощчин, Рудаков 2014]). В выборке ОНПЗ занятые в возрасте 15-24 лет могли также одновременно проходить обучение в образовательных организациях очной формы. 16 Динамика показателя доли группы NEET в целом, рассчитанной по отношению к численности всей молодежи в возрасте 15-24 лет, демонстрирует падение с 19\% в 1995 г. до 12\% в 2015 г.
} 
Таблица 2. Безработная NЕET-молодежь, ОНПЗ, 1995-2015 гг.

\begin{tabular}{|c|c|c|c|c|c|c|c|c|c|c|}
\hline \multirow{2}{*}{ Характеристики } & \multicolumn{5}{|c|}{ 15-19 лет } & \multicolumn{5}{|c|}{ 20-24 года } \\
\hline & 1995 & 2000 & 2005 & 2010 & 2015 & 1995 & 2000 & 2005 & 2010 & 2015 \\
\hline \multicolumn{11}{|c|}{ Пол, \% } \\
\hline Мужчины & 46,4 & 48,4 & 44,2 & 54,1 & 50,7 & 54,6 & 53,5 & 52,8 & 55,6 & 54,6 \\
\hline Женщины & 53,6 & 51,6 & 55,8 & 45,9 & 49,3 & 45,4 & 46,5 & 47,2 & 44,4 & 45,4 \\
\hline Средний возраст (лет) & 17,9 & 18,0 & 18,1 & 18,3 & 18,2 & 21,9 & 21,9 & 22,0 & 22,1 & 22,1 \\
\hline \multicolumn{11}{|c|}{ Тип поселения, \% } \\
\hline Город & 76,1 & 66,4 & 61,6 & 57,0 & 47,1 & 79,0 & 71,6 & 61,8 & 65,3 & 70,2 \\
\hline Село & 23,9 & 33,6 & 38,4 & 43,0 & 52,9 & 21,0 & 28,5 & 38,2 & 34,8 & 29,8 \\
\hline Состояние в браке, \% & 10,7 & 7,0 & 7,4 & 6,1 & 7,8 & 32,9 & 25,2 & 20,8 & 18,6 & 19,4 \\
\hline \multicolumn{11}{|c|}{ Уровень образования, \% } \\
\hline $\begin{array}{l}\text { Высшее профессиональное } \\
\text { (включая неполное высшее) }\end{array}$ & 0,1 & 1,3 & 1,8 & 0,0 & 0,2 & 7,4 & 11,4 & 17,2 & 18,9 & 28,2 \\
\hline Среднее профессиональное & 17,5 & 11,4 & 13,2 & 9,9 & 10,5 & 32,4 & 23,4 & 19,1 & 21,6 & 22,2 \\
\hline Начальное профессиональное & - & 16,4 & 15,1 & 17,6 & 14,7 & - & 15,3 & 16,9 & 19,0 & 15,5 \\
\hline Среднее (полное) общее & 49,0 & 40,9 & 40,9 & 51,4 & 51,1 & 45,7 & 32,9 & 31,6 & 30,5 & 26,7 \\
\hline Основное общее и ниже & 33,5 & 30,0 & 29,0 & 21,1 & 23,6 & 14,5 & 17,0 & 15,2 & 10,1 & 7,4 \\
\hline Отсутствие опыта работы, \% & 73,4 & 81,5 & 75,6 & 81,1 & 85,2 & 31,7 & 49,4 & 57,3 & 56,0 & 61,7 \\
\hline
\end{tabular}

В период 1995-2005 гг. в гендерной структуре безработной молодежи NEET в возрасте 15-19 лет превалировали женщины, а начиная с 2010 г. соотношение изменилось в сторону преобладания мужчин. Кроме того, риски безработицы среди молодежи этого возраста, не участвовавшей в обучении, к 2015 г. стали концентрироваться среди жителей села (соответствующая доля увеличилась с 24 до $53 \%$ ). По всей видимости, это связано с сокращением числа рабочих мест в сельской местности [Блинова, Вяльшина 2016]. Средний возраст представителей данной категории практически не менялся и составлял 18 лет. Таким образом, многие молодые люди попадали в данную категорию после окончания школы. Динамика образовательной структуры безработной молодежи NEET согласуется с этими результатами: почти половину данной категории во все годы составляла молодежь, получившая среднее общее образование; другую многочисленную категорию безработной молодежи NEET составляют те, кто имел лишь основное общее образование или вовсе не получил его. Их доля в рассматриваемый период несколько сократилась, однако в 2015 г. почти каждый четвертый безработный представитель NEET в возрасте 15-19 лет имел наиболее низкий уровень образования. Вступление в брак (официальный или гражданский) среди безработных представителей 
группы NEET в возрасте 15-19 лет распространено незначительно: в 1995 г. немногим менее 11\% состояли в браке, в 2015 г. - около 8\%. Показатель отсутствия опыта работы ${ }^{17}$ среди безработных NEET в возрасте 15-19 во все годы составлял более $70 \%$, но к 2015 г. увеличился до 85\%.

Безработная молодежь NEET в возрасте 20-24 лет - это преимущественно юноши, проживающие в городах, при этом в 2015 г. почти каждый пятый состоял в браке. В образовательной структуре данной группы в анализируемый период произошли большие изменения: если в 1995 г. значительную часть составляли те, кто получил среднее профессиональное образование, то к 2015 г. их место заняли выпускники вузов (доля которых за анализируемый период увеличилась с 7 до 28\%), а доли представителей остальных образовательных уровней уменьшились. Само по себе возрастание числа выпускников вузов среди молодежи NEET может свидетельствовать об ухудшении перспектив занятости молодых людей, т.к., согласно зарубежным исследованиям, высшее образование должно, напротив, значимо снижать вероятность попадания молодежи в категорию NEET (см., напр. [Eurofound 2012]). Выпускники учреждений высшего профессионального образования, как правило, доминируют в структуре NEET только в странах с высокими значениями этой категории, для которых характерен затрудненный и протяженный переход молодежи от учебы к работе [Eurofound 2016].

В условиях России указанные особенности безработных NEET могут объясняться массовизацией высшего образования. С одной стороны, высшее образование пользуется возрастающим спросом со стороны молодежи, с другой, выпускники некачественных вузов не обладают достаточными компетенциями и навыками для того, чтобы конкурировать за рабочие места, и становятся безработными ${ }^{18}$. Определенную часть молодежи NEET (относительно более благополучную) могут составлять и выпускники вузов с высокими зарплатными ожиданиями, которые не могут быстро найти удовлетворяющие их запросам рабочие места. Примечательно, что в 1995 г. опыт занятости отсутствовал лишь у трети безработных данной категории, в дальнейшем этот показатель значительно увеличился и к 2015 г. составил более 60\%. Таким образом, если в середине 1990-х гг. безработица среди группы NEET в возрасте 20-24 лет в большей степени была характерна для лишившихся прежнего места работы в результате происходящих макроэкономических трансформаций, то в последующие годы она стала уделом тех, кто ранее не совмещал учебу с работой и испытывает те или иные трудности с первичным входом на рынок труда.

Далее представлен анализ экономически неактивных представителей NEET. Следует напомнить, что данный тип незанятости доминирует в структуре группы NEET в России в обеих возрастных группах молодежи. Экономически неактивная молодежь NEET в возрасте 15-19 лет по своим характеристикам похожа на NEET-безработных сверстников. В структуре данной категории доли мужчин и женщин на протяжении 2000-2015 гг. были практически равны, при этом риски попадания в число представителей NEET и здесь с течением времени становились выше для жителей сел. Как уже отмечалось выше, согласно результатам

17 Вопрос о наличии предшествующего опыта работы в ОНПЗ задается только безработным. 
исследований, вступление в брак является одной из причин выпадения молодежи из системы занятости и образования. В середине 1990-х гг. каждый пятый экономически неактивный представитель NEET в возрасте 15-19 лет состоял в браке, однако к 2015 г. соответствующая доля упала до 12\%. Таким образом, к 2015 г. вступление в брак, по всей видимости, перестало быть причиной попадания в статус NEET-неактивности для молодежи данных возрастов. Ключевую роль в этом процессе в России играл низкий уровень образования: в рассматриваемый период почти половину экономически неактивной части молодежи NEET составляли молодые людей с основным общим образованием или вовсе без образования (43-50\%); другая многочисленная группа - те, кто получил среднее (полное) общее образование, их доля в 1995-2015 гг. равнялась 38-45\% (таблища 3).

Таблица 3. Экономически неактивная NEET-молодежь, ОНП3, 1995-2015 гг.

\begin{tabular}{|c|c|c|c|c|c|c|c|c|c|c|}
\hline \multirow{2}{*}{ Характеристики } & \multicolumn{5}{|c|}{ 15-19 лет } & \multicolumn{5}{|c|}{ 20-24 года } \\
\hline & 1995 & 2000 & 2005 & 2010 & 2015 & 1995 & 2000 & 2005 & 2010 & 2015 \\
\hline \multicolumn{11}{|c|}{ Пол, \% } \\
\hline Мужчины & 45,9 & 50,6 & 48,4 & 47,8 & 50,9 & 29,0 & 28,9 & 31,3 & 28,9 & 26,4 \\
\hline Женщины & 54,1 & 49,4 & 51,6 & 52,2 & 49,1 & 71,0 & 71,1 & 68,7 & 71,1 & 73,6 \\
\hline Средний возраст (лет) & 17,5 & 17,6 & 17,6 & 17,7 & 17,7 & 22,0 & 22,0 & 22,1 & 22,2 & 22,2 \\
\hline \multicolumn{11}{|c|}{ Тип поселения, \% } \\
\hline Город & 63,8 & 56,8 & 55,1 & 57,6 & 51,8 & 71,8 & 69,6 & 62,8 & 64,1 & 67,4 \\
\hline Село & 36,2 & 43,2 & 44,9 & 42,4 & 48,2 & 28,2 & 30,4 & 37,2 & 35,9 & 32,6 \\
\hline Состояние в браке, \% & 20,0 & 13,6 & 12,7 & 16,3 & 12,4 & 60,1 & 50,1 & 45,7 & 48,6 & 52,4 \\
\hline \multicolumn{11}{|c|}{ Уровень образования, \% } \\
\hline $\begin{array}{l}\text { Высшее профессиональное } \\
\text { (включая неполное высшее) }\end{array}$ & 0,3 & 1,7 & 1,4 & 0,0 & 0,1 & 6,9 & 12,3 & 13,8 & 6,9 & 16,8 \\
\hline Среднее профессиональное & 8,4 & 5,6 & 3,5 & 4,5 & 3,5 & 29,3 & 21,4 & 17,2 & 18,1 & 18,9 \\
\hline Начальное профессиональное & - & 8,1 & 8,7 & 8,0 & 7,9 & - & 10,4 & 14,6 & 15,2 & 13,2 \\
\hline Среднее (полное) общее & 41,1 & 38,3 & 37,5 & 42,0 & 45,3 & 45,9 & 33,4 & 33,0 & 36,2 & 35,3 \\
\hline Основное общее и ниже & 50,3 & 46,3 & 48,9 & 45,5 & 43,2 & 17,8 & 22,5 & 21,5 & 17,8 & 15,8 \\
\hline
\end{tabular}

В гендерной структуре экономически неактивных NEET в возрасте 20-24 лет во все года наблюдения доминировали женщины (более 70\%). Около половины экономически неактивных представителей NEET в возрасте 20-24 лет состояли в браке, при этом представители данной группы также отличались невысоким уровнем полученного образования. В структуре данной категории в 2000-2015 гг. преобладали те, кто окончил среднюю школу (33-36\%) или учреждение среднего профессионального образования (17-20\%). Среди экономически неактивных NEET в этих возрастах также наиболее широко представлены жители городов (63-72\%). 
Таким образом, данная категория NEET уходит из сферы рынка труда и образования во многом из-за изменений семейного статуса, хотя низкое качество полученного образования, по всей видимости, также играет свою роль. Экономически неактивная молодежь NEET не имеет возможности совмещать работу или учебу с занятостью в домашнем хозяйстве или же обладает ограниченными возможностями применения полученного образования на рынке труда.

Описанные особенности российской молодежи NEET позволяют сравнить ее с зарубежными представителями данной группы. С одной стороны, можно отметить, что молодежь NEET в России во многом похожа на своих сверстников из стран Европы, принадлежащих к первому, наиболее благополучному кластеру [Eurofound 2016]: так, доля молодежи NEET в общей численности 15-24-летних не превышает значений, характерных для Франции и Бельгии, а большинство молодежи NEET составляют экономически неактивные, для которых характерен невысокий уровень образования и которые покидают рынок труда по семейным обстоятельствам. В то же время на российском рынке труда присутствует категория безработных NEET, среди которых увеличивается доля молодых людей с высшим образованием, не имеющих опыта работы. Они получили высшее профессиональное образование и хотели бы работать, но их переход от учебы к занятости носит протяженный характер. Данная особенность российской молодежи NEET в определенной степени роднит ее с представителями аналогичной категории в странах второго кластера, в которых выпускники с высшим образованием составляют основную группу риска.

\section{Заключение}

В настоящей статье на данных за двадцатилетний период впервые были рассмотрены масштаб, динамика и социально-демографические характеристики специфической категории российской молодежи, которая в силу разных причин оказывается исключенной из сферы рынка труда и образования. Понимание масштабов, динамики и характеристик сегодняшних представителей NEET необходимо для определения ключевых болевых точек будущего состояния рынка труда и общества в целом, а также направлений политики молодежной занятости и поддержки доходов бедных семей. Как показал представленный выше анализ, в России в настоящий момент присутствие молодежи NEET в целом не представляет особо острой социальной проблемы для рынка труда и общества. В 1995-2015 гг. доля тех, кто находился за пределами рынка труда и образования, постоянно уменьшалась, в то время как доля обучающихся в образовательных организациях очной формы увеличивалась. Тем самым на время абсорбировалась значительная часть экономически неактивной молодежи. К 2015 г. доля молодежи NEET находилась на уровне среднеевропейских значений и по своим характеристикам она оказывалась похожей на представителей аналогичной категории в наиболее благополучных европейских странах. Важно подчеркнуть, что описываемое сокращение доли молодежи NEET происходило на фоне разнонаправленных изменений в экономике, характеризовавших выбранный период: показатель доли молодежи NEET, согласно данным Росстата по пяти выбранным для анализа временным точкам, никак не реагировал на ухудшение макроэкономической ситуации, вызванное последствиями кризисов 2008-2009 гг. и 2015-2016 гг. 
Тем не менее подавляющее большинство молодежи NEET разных возрастов обладают невысокими уровнями образования, что, по всей видимости, и препятствует им в нахождении занятости. Молодые люди в возрасте 15-19 лет попадают в данный статус сразу после окончания школы, при этом в 2015 г. по-прежнему была велика доля тех, кто оказался в состоянии NEET, не получив основного общего образования.

Другой важный негативный тренд связан со структурой безработных NEET, среди которых большинство вообще не имеет опыта работы, также растет доля выпускников с высшим образованием. В дальнейшем ситуация для них может усугубляться, поскольку они будут все больше проигрывать с точки зрения своих перспектив на рынке труда тем, кто наращивает необходимые для рынка труда навыки и компетенции. Еще одна важная тенденция связана с увеличением рисков попадания в данную категорию сельской молодежи: отсутствие достаточного количества рабочих мест в деревне и высокие издержки территориальной мобильности могут привести к их замыканию в статусе NEET. Наконец, исследование показало, что вовлечение молодежи NEET в систему высшего образования не способно решить проблему полностью, а лишь ненадолго прервать пребывание в статусе NEET. Из-за значительной неоднородности качества высших учебных заведений в статусе NEET могут все чаще оказываться выпускники некачественных вузов. Стимулирование представителей молодежи NEET к повышению квалификации и переобучению, которое имело бы четкую связь с требованиями рынка труда, а также создание рабочих мест на селе может привести к сокращению численности данной группы.

Настоящее исследование ставило своей целью описание первой общей картины динамики масштаба и структуры молодежи NEET в России за последние двадцать лет, происходившей на фоне различных макроэкономических изменений. Вне фокуса настоящей работы остались важные направления анализа данной молодежной категории. Среди них - изучение индивидуальных и семейных факторов, влияющих на попадание молодежи в статус NEET, при прочих равных условиях при помощи оценивания соответствующих регрессионных моделей; отслеживание карьерных треков тех, кто сумел покинуть группу NEET; сравнение социального положения молодежи NEET и представителей других депривированных групп российского общества; изучение динамики социального самочувствия, вызванной попаданием молодежи в статус NEET. Указанные направления анализа потребуют как дальнейшего изучения данных Росстата, так и привлечения панельных данных Российского мониторинга экономического положения и здоровья населения НИУ ВШЭ, и тем самым позволят уточнить представленные в настоящей статье результаты и расширить исследовательские представления о феномене молодежи NEET в России.

\section{Литература}

Андрущак Г.В., Гохберг Л.М., Забатурина И.Ю., Ковалева Н.В. (ред.) (2016) Индикаторы образования: 2016. Статистический сборник. М.: ВШЭ // https://issek.hse.ru/data/2016/02/20/1139690448/InObraz_2016_U.pdf

Блинова Т.В., Вяльшина А.А. (2016) Молодежь вне сферы образования и занятости: оценка сельскогородских различий // Социологические исследования. № 9. С. 40-49.

Бурдье П. (2004) Формы капитала // Радаев В.В. (ред.) Западная экономическая социология: хрестоматия современной классики. М.: РОССПЭН. С. 519-536. 
Варшавская Е.Я. (2015) Молодежь, исключенная из сферы занятости и образования, в странах ЕС и России // Вопросы статистики. № 4. С. 40-47.

Варшавская Е.Я. (2016) Российская NEET-молодежь: характеристики и типология // Социологические исследования. № 9. С. 31-39.

Рабочая сила, занятость и безработица в России (по результатам выборочных обследований рабочей силы). Статистический сборник (2016) // Федеральная служба государственной статистики // http://www.gks.ru/free doc/doc 2016/rab sila16.pdf

Рощин С.Ю. (2006) Переход «учеба-работа»: омут или брод? Препринт W̄P3/2006/10. М.: ВШЭ.

Рощин С.Ю., Рудаков В.Н. (2014) Совмещение учебы и работы студентами российских вузов// Вопросы образования. № 2. С. 152-179.

Рощин С.Ю., Рудаков В.Н. (2016) Влияние «качества» вуза на заработную плату выпускников // Вопросы экономики. № 8. С. 74-95.

Alfieri S., Rosina A., Sironi E., Marta E., Marzana D. (2015) Who Are Italian NEETS?: Trust In Institutions, Political Engagement, Willingness to Be Activated and Attitudes Toward the Future in a Group at Risk for Social Exclusion // Rivista Internazionale di Scienze Sociali, vol. 3, no 3, pp. 285-306.

Carcillo S., Fernández R., Königs S., Minea A. (2015) NEET Youth in the Aftermath of the Crisis: Challenges and Policies // OECD Social, Employment and Migration Working Papers. No. 164. OECD Publishing, Paris // http://dx.doi.org/10.1787/5js6363503f6-en

Coles B., Hutton S., Bradshaw J., Craig G., Godfrey C., Johnson J. (2002) Literature Review of the Costs of Being "Not in Education, Employment or Training" at Age 16-18. Research Report no 347. Department of Education and Skills, Nottingham // http://dera.ioe.ac.uk/4619/1/RR347.pdf

Elder S. (2015) What Does NEETs Mean and Why Is the Concept so Easily Misinterpreted? // ILO. Employment Policy Department. Youth Employment Programme. Technical Brief. No. 1 // http://www.ilo.org/wcmsp5/groups/public/\%40dgreports/\%40dcomm/documents/ publication/wcms_343153.pdf

Eurofound (2012). NEETs - Young People not in Employment, Education or Training: Characteristics, Costs and Policy Responses in Europe. Publications Office of the European Union, Luxembourg // https://www.eurofound.europa.eu/sites/default/files/ef_publication/ field ef document/ef1254en.pdf

Eurofound (2016). Exploring the diversity of NEETs. Publications Office of the European Union, Luxembourg // https://www.eurofound.europa.eu/sites/default/files/ef_publication/field ef document/ef1602en.pdf

Freeman R., Wise D. (1982) The Youth Labour Market Problem: Its Nature, Causes, and Consequences, Chicago: University of Chicago Press.

Gladwell D., Popli G., Tsuchiya A. A. (2016) Dynamic Analysis of Skill Formation and NEET Status // Sheffield Economic Research Paper Series. No. 2015016. The University of Sheffield // http://www.sheffield.ac.uk/polopoly_fs/1.471636!/file/ serps_2015016.pdf

Heckman J., Carneiro P. (2003) Human Capital Policy // NBER Working Paper Series. No. 9495 // http://www.nber.org/papers/w9495.pdf

Kosugi R. (2005) The Problems of Freeters and "NEETs" under the Recovering Economy// Social Science Japan, vol. 32, pp. 6-7.

OECD (2010) Off to a Good Start? Jobs for Youth, OECD Publishing, Paris // http://dx.doi.org/10.1787/9789264096127-en

OECD (1) (2013) Education at a Glance 2013: OECD Indicators. OECD Publishing, Paris // http://dx.doi.org/10.1787/eag-2013-en

OECD (2) (2013) How Difficult is it to Move from School to Work? Education Indicators in Focus, No. 13. OECD Publishing, Paris // http://dx.doi.org/10.1787/5k44zcplv70q-en

OECD (2015) Youth Unemployment Rate (indicator) // http://dx.doi.org/10.1787/c3634df7-en

OECD (2016) OECD Employment Outlook 2016. OECD Publishing, Paris // http://dx.doi.org/10.1787/empl_outlook-2016-en

Scarpetta S., Sonnet A., Manfredi T. (2010) Rising Youth Unemployment During the Crisis: How to Prevent Negative Long-term Consequences on a Generation? // OECD Social, Employment and Migration Working Papers. No. 6.

Wadsworth J. (2013) Youth and The UK Labour Market. Growing up in Recession Britain a MISOC Event Presenting New Research. Presentation materials. 


\title{
The NEET Youth in the Russian Labor Market
}

\author{
A. ZUDINA*
}

\begin{abstract}
*Anna Zudina - PhD in Sociology, Research Fellow, Center for Labor Market Studies, National Research University Higher School of Economics. Address: 20, Myasnitskaya St., Moscow, 101000, Russian Federation. E-mail: azudina@hse.ru
\end{abstract}

Citation: Zudina A. (2019) The NEET Youth in the Russian Labor Market. Mir Rossii, vol. 28, no 1, pp. 140-160 (in Russian). DOI: 10.17323/1811-038X-2019-28-1-140-160

\begin{abstract}
NEET, or young people aged 15-24 who are Not in Employment, Education or Training deserve their special name in international statistics. They are cut off both from education and the labor market, and will most likely face difficulties with further employment and inclusion into society in general. The present paper analyzes the scale, the dynamics and the socio-demographic features of NEET in Russia using data from Labor Force Survey (LFS) data, 1995-2015, collected by the Federal State Statistics Service. The results indicate that, in the period analyzed, the share of NEET decreased significantly, which came as a result of the active involvement of youth in education. According to LFS, the share of NEET did not respond to any negative macroeconomic shocks, i.e. the crises of 2008-9 and 2015. However, NEET in Russia are consistently dominated by those whose relationship with the labor market is the weakest, i.e. those who are out of the labor force. The vast majority of unemployed NEETs have absolutely no labor market experience. The socio-demographic profile of NEET reveals that the likelihood of falling into this group is negatively associated with the level of education, and positively with the reducing employment opportunities in rural areas. The majority of unemployed NEETs have higher education, which suggests that further educational expansion might force an even greater share of young people into NEET.
\end{abstract}

Key words: youth unemployment, labor force, labor market, Russia, NEET youth, Labor Force Survey

\section{References}

Alfieri S., Rosina A., Sironi E., Marta E., Marzana D. (2015) Who Are Italian NEETS?: Trust In Institutions, Political Engagement, Willingness to Be Activated and Attitudes Toward the Future in a Group at Risk for Social Exclusion. Rivista Internazionale di Scienze Sociali, vol. 3, no 3, pp. 285-306.

Andrushchak G.V., Gokhberg L.M., Zabaturina I.Yu., Kovaleva N.V. (eds.) (2016) Idikatori obrazovaniya: 2016. Statisticheskij sbornik [Education Indicators: 2016. Statistical 
Yearbook]. Moscow: HSE. Available at: https://issek.hse.ru/data/2016/02/20/1139690448/ InObraz_2016_U.pdf, accessed 14.01.2019.

Blinova T.V., Vyalshina A.A. (2016) Molodezh' vne spheri obrazovaniya i zanyatosti: otsenka selsko-gorodskikh razlichij [Youth out of Education and Employment: Evaluating Rural-Urban Differences]. Sotsiologicheskie issledovaniya, no 9, pp. 40-49.

Bourdieu P. (2004) Formi kapitala [Forms of Capital]. Zapadnaya ekonomicheskaya sotsiologiya: khrestomatiya sovremennoj klassiki [Western Economic Sociology: the Handbook of Modern Classics] (ed. Radaev V.V.), Moscow: ROSSPEN, pp. 519-536.

Carcillo S., Fernández R., Königs S., Minea A. (2015) NEET Youth in the Aftermath of the Crisis: Challenges and Policies. OECD Social, Employment and Migration Working Papers. No. 164. OECD Publishing, Paris. Available at: http://dx.doi.org/10.1787/5js6363503f6-en, accessed 14.01.2019.

Coles B., Hutton S., Bradshaw J., Craig G., Godfrey C., Johnson J. (2002) Literature Review of the Costs of Being "Not in Education, Employment or Training" at Age 16-18. Research Report no 347. Department of Education and Skills, Nottingham. Available at: http://dera.ioe.ac.uk/4619/1/RR347.pdf, accessed 14.01.2019.

Elder S. (2015) What Does NEETs Mean and Why Is the Concept so Easily Misinterpreted? ILO. Employment Policy Department. Youth Employment Programme. Technical Brief. No. 1. Available at: http://www.ilo.org/wcmsp5/groups/public/\%40dgreports/\%40dcomm/ documents/publication/wcms_343153.pdf, accessed 14.01.2019.

Eurofound (2012). NEETs - Young People not in Employment, Education or Training: Characteristics, Costs and Policy Responses in Europe. Publications Office of the European Union, Luxembourg. Available at: https://www.eurofound.europa.eu/sites/default/files/ef publication/field_ef_document/ef1254en.pdf, accessed 14.01.2019.

Eurofound (2016). Exploring the diversity of NEETs. Publications Office of the European Union, Luxembourg. Available at: https://www.eurofound.europa.eu/sites/default/files/ ef_publication/field_ef_document/ef1602en.pdf, accessed 14.01.2019.

Freeman R., Wise D. (1982) The Youth Labour Market Problem: Its Nature, Causes, and Consequences, Chicago: University of Chicago Press.

Gladwell D., Popli G., Tsuchiya A. A. (2016) Dynamic Analysis of Skill Formation and NEET Status. Sheffield Economic Research Paper Series. No. 2015016. The University of Sheffield. Available at: http://www.sheffield.ac.uk/polopoly_fs/1.471636!/file/ serps_2015016.pdf, accessed 14.01.2019.

Heckman J., Carneiro P. (2003) Human Capital Policy. NBER Working Paper Series. No. 9495. Available at: http://www.nber.org/papers/w9495.pdf, accessed 14.01.2019.

Kosugi R. (2005) The Problems of Freeters and "NEETs" under the Recovering Economy. Social Science Japan. vol. 32, pp. 6-7.

OECD (2010). Off to a Good Start? Jobs for Youth, OECD Publishing, Paris. Available at: http://dx.doi.org/10.1787/9789264096127-en, accessed 14.01.2019.

OECD (1) (2013). Education at a Glance 2013: OECD Indicators. OECD Publishing, Paris. Available at: http://dx.doi.org/10.1787/eag-2013-en, accessed 14.01.2019.

OECD (2) (2013). How Difficult is it to Move from School to Work? Education Indicators in Focus, No. 13. OECD Publishing, Paris. Available at: http://dx.doi.org/10.1787/5k44zcplv70q-en, accessed 14.01.2019.

OECD (2015). Youth Unemployment Rate (indicator). Available at: http://dx.doi.org/10.1787/c3634df7-en, accessed 14.01.2019.

OECD (2016). OECD Employment Outlook 2016. OECD Publishing, Paris. Available at: http://dx.doi.org/10.1787/empl_outlook-2016-en, accessed 14.01.2019.

Rabochaya sila, zanyatost' i bezrobotitsa v Rossii (po rezultatam vyborochnikh obsledovanij rabochej sili. Statisticheskij sbornik [Labour Force, Employment and Unemployment in Russia (According to Labour Force Surveys). Statistical Yearbook] (2016). Federal State Statistics Service. Available at: http://www.gks.ru/free_doc/doc_2016/rab_sila16.pdf, accessed 14.01.2019.

Roshchin S.Yu. (2006) Perekhod «ucheba-rabota»: omut ili brod? [The School-to-WorkTransition: a Slough or a Ford?]. WP3/2006/10, Moscow: HSE. 
Roshchin S.Yu., Rudakov V.N. (2014) Sovmeshchenie ucheby i raboty studentami rossijskikh vuzov [Combining Work and Study by Russian Higher Education Institution Students]. Voprosy obrazovaniya, no 2, pp. 152-179.

Roshchin S.Yu., Rudakov V.N. (2016) Vliyanie kachestva vuza na zarabotnuyu platu vipusknikov [The Impact of University Quality on Wages of Russian University Graduates]. Voprosy ekonomiki, no 8, pp. 74-95.

Varshavskaya E.Ya. (2015) Molodezh', iskluchennaya iz spheri zanyatosti i obrazovaniya, v stranakh ES i Rossiii [Youth Excluded from Employment and Education in EU Countries and in Russia].Voprosy statistiki, no 4, pp. 40-47.

Varshavskaya E.Ya. (2016) Rossiiskaya NEET-molodezh': kharakteristiki i tipologiya [Russian NEET-Youth: Its Characteristics and Typology]. Sotsiologicheskie issledovaniya, no 9, pp. 31-39.

Scarpetta S., Sonnet A., Manfredi T. (2010) Rising Youth Unemployment During the Crisis: How to Prevent Negative Long-term Consequences on a Generation? OECD Social, Employment and Migration Working Papers. No. 6.

Wadsworth J. (2013) Youth and the UK Labour Market. Growing up in Recession Britain a MISOC Event Presenting New Research. Presentation materials. 